\title{
Book reviews with a note about Knowledge Management and Human Resources
}

\author{
Reading maketh a full man; conference a ready man and writing an exact man. \\ Francis Bacon, Essays, 1625.
}

\section{Introduction}

Knowledge Management (KM) and Human Resources (HR) management are two phrases appearing in a various publications rather frequently at the moment. Are they simply activities which any good Information manager would have already taken in his stride, or is there some good reason for the hype that they are currently receiving? The answer to both questions is yes.

The good manager would like to receive some recognition for tangible benefits which are the outcome of his efforts. There's no harm in accentuating the positive. You make your department more visible by introducing new notions. The two phrases have a ring to them that is lacking in that vague intangible function "Information Management". If you search the Web using AltaVista with the phrase "human resources AND knowledge management" you will receive 1858 hits (4th August 1998) but limiting the search to "since July 1st" reduces it to 24 . Several are advertisements for consulting services. One company says that it developed "knowledge-based systems for the legal field.... The rise of the Internet is having an impact on Human Resources".

\section{Knowledge Management (KM)}

The two books to be reviewed cover KM among other things, but what is the difference between information management and knowledge management? Is KM the next wave of hype attempting to breathe life into information science/technology? What is the difference between "information" and "knowledge"? Quoting from the International Encyclopedia of Information and Library Science:

Information: an assembly of data in a comprehensive form capable of communication and use.

Knowledge: information evaluated and organised in the human mind so that it can be used purposefully.

To the more academically inclined, KM's importance in artificial intelligence seems to be of special interest. Others use the phrase more generally without differentiating between knowledge management and information management. More will be learned when the subject is discussed at a workshop during the Member's day of the Institute of Information Scientists in September, 1998.

"Ontology" - a less familiar word - is a related topic. Vickery [1] refers to its definition, when applied to knowledge-based artificial intelligence system applications, as "an explicit specification of a conceptualisation". "Enterprise ontology" usually refers to corporate applications. Vickery defines it as "a collection of terms and definitions relevant to business enterprises". The people at the University of 
Edinburgh [2] working on the Enterprise Project agree with that definition but in their description of "an enterprise ontology", they add: - “... we describe our experiences in using the Enterprise Oncology" so it is more than just a collection of terms.

When "Knowledge Management" is used to describe aspects of artificial intelligence research, it is dealing with an an ontology domain which has been investigated since the eighties with mixed results. Newell's early paper about knowledge bases in AI [3], written when he was at Carnegie-Mellon University, has been cited over two hundred and fifty times in recent years. It is briefly discussed by Vickery [1] in his 1998 article. But in this review I am considering KM in the context of corporate information management. For example, O'Leary [4] says that in the event of "downsizing" (a euphemism for sacking people): - "Unless the knowledge of employees has been captured before they leave there can be a loss of critical information". He continues: - "Can we create a system that will capture company-wide knowledge and make it widely available to all its members?"

So at last we come to practical aspects of $\mathrm{KM}$ which should interest readers of $I S \& U$. Is it something new for which new systems have been developed to dig out and preserve important company-generated knowledge?

Some people answer this question very positively, but little has been published in respect of specific KM "systems". It appears that well known rather than completely new techniques are used to collect and utilize knowledge. But O'Leary [4] believes in KM. He says: - "Knowledge discovery is a new and rapidly evolving discipline that uses tools from artificial intelligence, mathematics and statistics to tease knowledge out of data warehouses." Good management of It has resulted in in a wide range of applications including fraud analysis, credit card analysis, security, customer analysis and product analysis.

Davenport mentions KM quite briefly in his book, reviewed below, although he discusses successful KM projects enthusiastically in [5]. He says that there was "a commitment of human and capital resources, and four similar kinds of objectives - the creation of repositories for storage and availability, facilitation of knowledge transfer, encouragement for knowledge creation, transfer and use", and "managed knowledge as an asset on the balance sheet". Earlier in the book he seems to be less enthusiastic: - "For years people have referred to data as 'information'; now they have to resort to the high-minded 'knowledge' to discuss information - hence the current boom in 'knowledge management'."

The chapter entitled "Knowledge management: why get involved with The Internet?" in the second book reviewed below, is mainly about using the Web. The management of the retrieved material is not much discussed.

Some people believe that KM has received more hype than it deserves. They think it is simply a highsounding new phrase describing something that any good information manager will be doing anyway. Taylor [6] says that "Evidence coming out of the US suggests that there is much hype, uncertaintly, and confusion surrounding knowledge management". He suggests that "often more knowledge leads to greater ignorance. As more is known more is sought... leading to an ever-increasing information overload and frustration."

Whatever may be the definitions used for information and knowledge, I have always visualised my collection of thousands of systematically organised indexed pages taken from journals, reprints, reports, etc., to be "material containing information about other people's knowledge". Is this a "Knowledge Base" and what's new about it? The answer is very little - it appears to be the same kind of database as is described by O'Leary [4]. O'Leary is a prolific author who works at the University of Southern California. In the section of his article entitled "Searching for Knowledge" he mentions the AltaVista, Excite, Infoseek, Lycos, WebCrawler and Yahoo search engines for the Web. For me, these are simply extremely 
useful tools created because the remarkable growth of the un-indexed material on the Web was crying out for attention.

\section{Human Resources}

"Human resources" is an unspecific phrase but "human resources in organisations" has a meaning which sounds more interesting. During a Web search I came across a curious document which is enlightening but unattributed - no author or organisation is listed. It quotes a comment by one Michael Hammer - evidently a well-known person in this field. The title of the Web piece is "HR: Strategies and Tactics".

The core process of HR, says this article, is to "make certain the enterprise has the requisite people in place to accomplish the goals of the organisation" or, as stated by one Chief Executive Officer "I want the right people in the right place doing the right stuff now". The article continues: "Today we are looking at work to be done rather than jobs. The rate of organisational change is too fast for jobs to keep up." Some organisations have HR departments. An article in the Harvard Business Review [8] describes the problems of the department: "The new CEO doesn't have a flair for attracting and retaining talented people, and the HR department hasn't been able to pick up the slack". HR has got its own journal Human Resource Management.

The second book to be reviewed is all about HR although the phrase is only used once. In the first chapter under the heading "Human Resources" Colin Rochester says "Volunteering is not restricted to the voluntary sector". A unique challenge is faced in the situation when "paid staff and volunteers work side-by-side often carrying out the same tasks".

\section{Books}

Information Ecology, Thomas H. Davenport, Oxford University Press, 1997, 255 pp., £25, ISBN 0 195111680.

In his first chapter Davenport says: - "The status quo approach to information management - invest in new technology - just doesn't work. Instead, managers need a holistic perspective, one that can weather sudden business shifts and adapt to ever-changeable social realities. This new approach which I shall call Information Ecology emphasises an organisation's entire information environment."

This book is business oriented - a "List of firms studied" is provided and examples of information practice within the firms appear quite often. Strategy, politics, behaviour and culture, staff, processing and ecology implementation are discussed. There are many references and a good index. I cannot understand the benefit of providing chapter by chapter self-contained bibliographies at the end of the book. They should either be at the end of each chapter, or in a single list at the end. But that is a minor criticism. This in one of the best books I have seen about the practical aspects of information management.

Davenport devotes several pages to "real-world ecology" at Standard Life, Edinburgh which he says is "one of the world's largest and most profitable mutual life insurance companies" with revenues over $£ 5$ billion. We may assume that's how he thinks it should be done.

The author makes the usual criticisms of most libraries but he has some novel ideas about improvements. While television is often a "vaste wasteland" he believes that the television industry "has been fantastically successful in gaining viewers and changing their information behaviours... the TV industry's approach to information provides a much more useful model". He says, that that industry has man- 
agers which are obsessed with usage and users, content is critical, technology does not get in the way, information is bundled effectively, and distribution is multiple (over the air or via satellite or cable).

Later in the book Davenport discusses an imaginary ideal drug company which does everything right. The company employs a research information Czar who manages the information behaviour of the firm. I am not sure about the attitude adopted by mainland Europe companies about information sharing versus information confidentiality. In my experience of British and American companies I have usually found that they resemble their governments - the British are secretive, the Americans expansive.

Information Management in the Voluntary Sector, edited by Diana Grimwood-Jones and Sylvia Simmons, Aslib, London, 1998, 450 pp., £35 (£28 to Aslib Corporate Members), ISBN 0851423949.

Quite an effort must have been made to marshal the group of 25 authors who have contributed to this book. They successfully fulfill its aims which are discussed below. The chapters are often well referenced, there is an appendix which lists the Internet addresses of relevant information resources followed by short biographies of the contributors and a comprehensive index.

Many people work for voluntary, not for profit, or non-governmental organisations. According to one of the authors, in the UK alone there may be up to 240,000 voluntary organisations employing up to 620,000 people with revenues in 1995 totalling $£ 15$ billion! The scale of world-wide voluntary activities must be enormous. Household names engaged in a wide variety of services come to mind - Amnesty International, Christian Aid, Child Poverty Group, The NSPCC, Save the Children, MENCAP, Greenpeace and Shelter, for example. Most are much smaller than these organisations.

Before attempting to review the book, I thought that I should find out more about the voluntary sector. My knowledge about this field is inadequate. Finding it difficult to discover more, I decided to try the "author term" approach. An author known to be an authority soon leads to informative literature and may help you to find out what are the journals of the field. The author of the chapter "Introducing the Voluntary Sector", Colin Rochester, cites David Billis (1993 and 1996) as an authority, and discusses his work. Being able to use the Web of Science [7], I found a 1998 article by Billis and Glennerster in the Journal of Social Policy; it has 44 references. A 1998 paper by Margaret Harris in Policy and Politics has 6 references in common with the Billis paper, so it is likely to be about a similar subject. In fact both are about the characteristics of the voluntary sector.

The book's authors take care to tell you what the voluntary sector is all about. Rochester says that the research community of the sector "can support three international academic journals" without naming them. I think they are probably The Non-profit and Voluntary Sector Quarterly, Veritas, and the Journal of Non Profit and Voluntary Sector Marketing. Billis et al. say, that voluntary organisations have a comparative advantage over other sector agencies enabling them to "overcome problems of principal-agent gap, median voter reluctance, weak messages from politicians to staff and lack of market interest". I am starting to learn something about the subject in order to make some sensible (I hope) remarks about the book I am reviewing.

What is different between information management in this area and other areas? As one of the editors, Sylvia Simmons, says in her chapter about information and policy, the role of information professionals is "no different to that contributed by information units in other sectors - academic, commercial, or industrial. There are, however, fundamental features in the culture, context, and ethos of the voluntary sector which warrant special consideration."

It says in the Preface that the book is designed for three groups of readers - general managers without much experience of information management, staff seeking practical guidance, and tutors and trainers who need to know about current developments. Although information management requirements in this 
field are similar to requirements elsewhere, the need for a book catering specifically for this sector are perhaps indicated by the remarks of Graham Bennett in Chapter 7: - "Many of the largest, most established charities and voluntary organisations in the United Kingdom" (and no doubt in other countries) "have reached old age, and are finding that in many cases they are out of touch with the culture and environment of their users".

The publication is divided into several parts - The Voluntary Sector: the Context; Technical and Professional Issues; Case Studies; Appendix. The style and culture of the voluntary sector and the special kinds of marketing and campaigning needed are discussed in detail as are financial reporting, international aspects and copyright.

Jacqueline Cropley makes the point in Chapter 11 that "Library automation for voluntary organisations allows services to be delivered far and wide with minimal outlay. It is becoming an invaluable method of reaching widespread and scattered communities." Cropley continues: - "links can be established with anyone who has Internet access" - a far better arrangement than methods of communication formerly used.

Case Study 4 is a very good example of Human Resources backed by Information Technology being used by a voluntary organisation to good effect.

Caroline Bradley, the development officer at Alcohol Concern, writes about "Launching a Web page: Alcohol Concern". This is a misleading title. The piece is about launching a Web site. The description of how the organisation set about it and the costs incurred show what can be done by a small organisation with an information unit of four people. AC decided to establish a partnership with the publishing company Dolomite, who already published AC's printed directory and who already had Internet experience. One factor in making this decision was trust. "We were confident that Dolomite would fully explain, in a language we were able to understand, resource requirements laying out clear options and making recommendations in out best interests". By being able to organise and run a Web site, on this basis, Alcohol Concern was extremely fortunate. As Bradley says: - "We would be able to service the site without having to learn techniques or procedures that we didn't need to know".

The site, launched in September 1996, can be found at http: //www.alcoholconcern.org.uk. It is attractively designed and easy to use. The home page contains a number of ikons illustrating the services available. When an ikon is clicked the service is revealed. Services include "Alcohol problems: what to do?", access to the services directory and so on. A detailed index is also provided. Clicking an index term takes you to the item indexed. The total cost has been $£ 2500$. This includes domain name registration, site submission to search engines, design consultancy and graphics, text conversion to HTML and organising server storage space. Ruining costs are about $£ 50$ per month (including tax).

After a year of availability the site averages about 700 " 'use' sessions" per week. People from all over the world use the site. The most frequent users come from the United States followed by UK, Canada, and Australia. Anyone setting up a Web site will find that this Case study contains some very useful and practical information.

The other case studies also include a great deal of useful information about organising information units. Activities at the Leonard Cheshire organisation, Christian Aid, the NSPCC, Charities Aid Foundation, and the Child Rights Information Network are described.

In a way it's a pity that this book is entitled Information Management in the Voluntary Sector. A more descriptive title would be Marshalling Human Resources to Provide Efficient Information Services. There seems to be something about many Voluntary Organisations which enables them to produce very useful results with a small staff and at low cost. 


\section{References}

[1] B.C. Vickery, Ontologies, Journal of Information Science 23(4) (1997), 277-286.

[2] M. Uschold, M. King, S. Moralee and Y. Zorgios, The enterprise ontology, Knowledge Engineering Review 13 (1998).

[3] A. Newell, The knowledge level, Artificial Intelligence 18 (1982), 87-127.

[4] O’Leary and E. Daniel, Enterprise knowledge management, Computer 11(3) (March 1998), 54-61.

[5] T.H. Davenport, K.M. De Long and K.C. Beers, Successful knowledge management projects, Sloan Management Review 39(2) (1998), 43 et seq.

[6] Taylor and David, Knowledge management - hot button or hot air?, Computer Weekly, 2nd July 1998, p. 26.

[7] T. Cawkell, Checking research progress on "image retrieval by shape-matching" using the Web of Science, to be published in Aslib Proceedings, 1998.

[8] R. Galford, Why doesn't this HR department get any respect?, Harvard Business Review 76(2) (Mar--Apr. 1998), 24. 